\title{
STOCHASTIC BEHAVIOUR OF HEAT WAVES AND TEMPERATURE IN HUNGARY
}

\author{
A. RÉVÉSZ \\ Corvinus University of Budapest, Faculty of Horticultural Sciences, Department of \\ Mathematics and Informatics \\ 1118 Budapest, Villányi út 29-43, Hungary \\ (phone: +36-1-482-6181; fax: +36-1-466-9273) \\ e-mail:andras.revesz@uni-corvinus.hu \\ (Received $25^{\text {th }}$ October 2008 ; accepted $13^{\text {rd }}$ December 2008)
}

\begin{abstract}
One of the adverse effects of climate change is the proliferation of heat waves. Our investigations show that according to the most widely accepted climate change scenarios heat waves are expected to be essentially longer and hotter than in the past. It might happen that events we now define as heat waves last through entire summer. Although it will not be general, the length and intensity of present heat waves could also multiply. Based on data provided by some global circulation models, we might be face an event that exceeds the hottest heat waves of the $20^{\text {th }}$ century by as much as $12^{\circ} \mathrm{C}$. This study also offers a survey of the methodology of heat wave definition. Besides traditional calculations, we present two unconventional methods by introducing minimum and maximum temperature heat waves. We show in what points this approach is different from those usually adopted and what extra information it may offer. As an extension of the usual studies, with considering the length of events, we analyse the development of two variants - temperature and duration - and, as a result, classify the extreme heat events according to both length and intensity.
\end{abstract}

Keywords: Duration of heat waves, frequency of heat waves, distribution of heat waves, minimum and maximum temperature heat waves.

\section{Introduction}

In this study we show that, according to the current climate scenarios, the change of the climate in Hungary may have serious effect on society from the point of human beings, veterinary as well as economy. For this investigation we made statistical and risk analysis calculations on historical meteorological time series data and three selected scenarios. Our research was conducted within the frames of the project "Preparing for Climate Change: Environment - Risk - Society (KLIMAKKT) (Harnos, 2007). The model runs in the centre of our investigation were the three runs of the two scenarios also studied by the other participants of the project. As IPCC - playing a leading role in climate change research - has set down four possible socio-economic scenarios (IPCC, 2007) widely used as input parameters by the research centres studying climate change for their own mathematical models, we have decided to examine the same scenarios. Our possibilities do not allow us to develop the circulation models of our own, in fact, the enormous amount of calculation these require have even prevented us from running existing models and therefore we have to be satisfied with models runned by other research institutes (PRUDENCE, 2007) and use them as inputs for our own investigation. With several institutes involved in the latest research by the IPCC, we have had several dozens of model runs at our disposal. The researchers in the project have selected three of these, only, to make sure that a comparable studies of the possible changes emerge from the research in the various fields. Accordingly, we also work with these three runs in the following study, namely the A2 and B2 scenarios of Hadley 
Center and the A2 scenario of the Max Planck Institute. These new runs all refer to the time interval 2070-2100 and contain the daily meteorological data (minimum, maximum and average temperature) required for our research. We compared these with the 100 year (1901-2000) meteorological time series data of Budapest and Debrecen. For much of our calculations we used a module containing time series and risk factors, created specifically for our research (Szenteleki at al., 2007.) and included in the software package of KKT (Council for Climatic Research) (Szenteleki et al., 2007.) developed to create a standard database in the KLIMAKKT project.

The main goal of our research was to determine whether a change can be expected in the frequency and intensity of heat waves and if so, what would be its direction and volume. Researchers and public at large received the first warnings of the extraordinary effects of heat wave in Chicago in 1995, followed by one with tragic consequences in Paris in 2003 (Poumadère et al., 2004). Dramatic processes were triggered off in both cases by extraordinary meteorological events (Schär at al, 2004). To further aggravate the problem, the leaders and public authorities of the towns affected were caught unprepared for the tasks required by the extraordinary heat. In the absence of any previous experience, they had no really idea what they were required to do. From the retrospect of a few years, the specialists analysing the events revealed that although it is true that extraordinarily high mortality was caused by the heat, good communication might have prevented the tragedy. By now, we all know that people on the periphery of society are hit hardest by heat waves, including in the first place those over 65, people with disease, physical or mental disabilities and the poor. Both memorable heat waves drew the highest number of victims from people with multiple disadvantages, in other words, the poor, the elderly and the sick. The reason for this is not simply their inability to look after themselves, but many other ones related to the absence of information and money. There were hardly any air conditioners in the suburbs of Chicago in the 90s and in fact, there had not even been ventilators to ease the sensation of heat in the homes of the deceased. To add to the problem, public safety has been deplorable in these districts, discouraging the elderly from going out in the streets in search of a cooler place. This was not a problem in Paris where the absence of air conditioners was. To go from bad to worse, air conditioning in those days was inadequate in public institutions and in many of the hospitals as well as in private homes. Both cities had a shortage of ambulances and hospital beds. In Paris, unfortunately, casualties also filled the morgues, creating a truly extraordinary situation for the town leadership.

Similar heat wave would probably be faced at an improved level of preparedness in the more highly developed big cities of the world holding out the hope that appropriate action plans and better communication might keep down the number of deaths caused by heat-related stress. However, there are also other dangers threatening areas other than human health. Among these, infrastructural problems are in the first place. Extreme heat might temporarily disable the railways the consequence of whichcan paralyse public transport. Lasting heat may cause similar problems in major towns where temporary stoppages in tram or underground (subway) traffic may bring the public transport system to a complete standstill and that might also lead to complete blockages of the road traffic. The traffic situation will be further deteriorated by commuters travelling daily from the agglomeration surrounding all the major cities who, once the commuter's trains stop working, will all be forced to use their cars. Electricity might be another infrastructural problem. The spread of air conditioners has already significantly increased electric energy consumption in summer. Some big cities are already facing 
capacity problems that might grow with the expected warming. As examples of the past few years have shown, in situation of narrow capacities, even a slight break-down in a period with outstandingly hot temperature might cause a blackout of entire districts or regions. Nuclear power plants, those otherwise reliable pillars of the electric energy network also become a source of potential danger. This is because nuclear reactors are usually built by rivers whose water provides adequate cooling for the reactor. The problem is that above a certain temperature the safety of this operation cannot be ensured and high temperature might necessitate a temporary shutdown. Long periods of dry and warm weather may cause the same problem by reducing the water level of certain rivers. This situation might be eased by the latest EU directive on energy, instructing members to rely as much as possible on the various renewable resources of energy, including, in the first place, solar energy, to meet the electric energy demands of the growing consumption of summer period.

Events triggered by heat wave that were surveyed so far represent but a few of all the possible problems. There are several issues on which we do not have enough information but assumed to be problematic. These are the security of drinking water supplies, the outburst of epidemics, reduced working ability, accidents induced by lack of concentration caused by the heat, etc. Our experiences justify the requirement to pay more attention to heat waves. We had embarked on this study in order to find out whether the frequency and intensity of heat waves change in the period examined.

\section{Definitions}

What is a heat wave? One might be prompted to answer the question by saying that a heat wave is a hot spell of some length. True, but the question is how hot and what length? The answers may be as manyfold as the number of institutions or bureaus releasing studies on the issue. As an added complication, heat waves have meteorological or ecological consequences over and above the obvious humane and infrastructural impacts. So rather than accepting a general definition, we must consider the object of scrutiny. A more comprehensive approach is possible in the case of heat that might be harmful to human health, defined by the authorities as the ,heat alarm threshold" in various countries.

In way of providing some kind of guideline, the World Meteorological Organization has come up with a definition by which we have a heat wave when the daily maximum temperature, over more than five consecutive days, exceeds by at least $5^{\circ} \mathrm{C}$ the average of the maximum daily temperatures of the same calendar days in the period between 1961-1990.

As a similar example, we might quote the Dutch definition by which a heat wave is an event when the daily maximum temperature over 5 consecutive days exceeds $25^{\circ} \mathrm{C}$ and for at least 3 days it reaches the $30^{\circ} \mathrm{C}$ mark.

The criterion for calling a heat wave alarm is different in the various states of the US, but they also have a guideline with the definition by the National Weather Service which says that a heat wave stricken period is one in which the maximum temperature is over $32.2^{\circ} \mathrm{C}$ for at least three days. Heat waves are also classified by their degree of being dangerous, with various levels and action programmes established to provide the cornerstones of categorization. Here night-time maximum temperatures are also considered over and above the daily maximums. A more sophisticated concept than the temperature-based one is used in the form of a heat index, a derived quantity calculated 
from the values of temperature and humidity. The essence of this calculation is that it can express the human thermal sensation. Without doubt, in a human context, the heat index can be used with much greater accuracy than the temperature alone, for the current study however, we had no humidity data at our disposal, so we had to rely only on those of temperature. It should also be noted that the absence of data was not the only reason why we did not use a heat index. As discussed earlier, heat waves do not only hit people, they may also have an adverse effect on other beings, the infrastructure, economic performance, etc. Of all the negative effects of heat waves only those with a human implication can be analysed if we rely on thermal sensation in our investigation. Therefore we drew up analyses in which we distinguished among heat waves on the basis of their intensity as well as length. First, let us look at the official Hungarian definition - based on a study that has been a joint project of the National Institute of Environment Health of the National Center for Public Health - NCPH-NIEH (OKKOKI)1, the Budapest Office of the National Public Health and Medical Officer Service - NPHMOS (ÁNTSZ) and the Hungarian Meteorological Service - HMS (OMSZ) that points to days with an average temperature above the daily average temperature monitored at a $97 \%$ frequency $\left(26.6^{\circ} \mathrm{C}\right)$. By that, a heat wave is an event in which the daily average temperature is above $26.6^{\circ} \mathrm{C}$ on three consecutive days.

\section{Results}

\section{The frequency of heat waves on the basis of the official Hungarian definition}

Let us compare the distribution of the length of the heat waves by this definition in Budapest and Debrecen in the periods between 1901-2000 and 1970-2000. We need these two different time intervals to be able to decide which one to use as a base period for comparison in our subsequent enquiry.

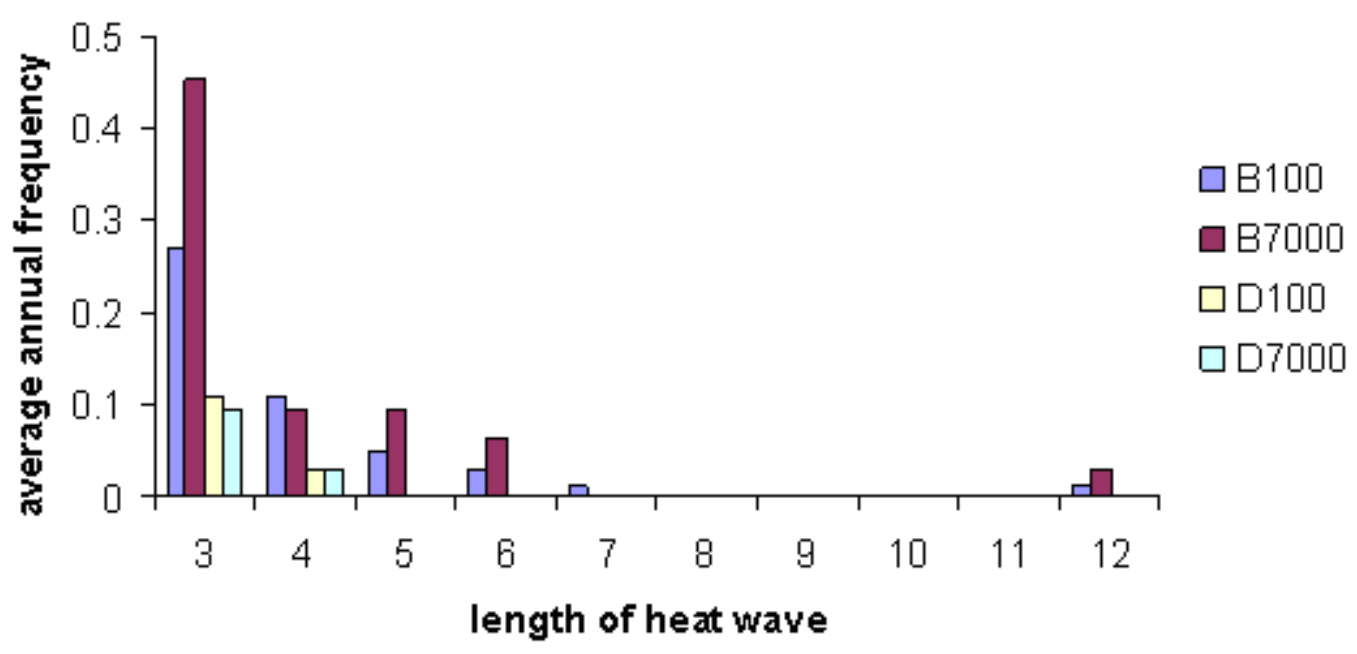

Figure 1. Distribution of heat waves in Budapest and Debrecen between 1901-2000, (B100, D100) and 1970-2000 (B7000, D7000)

\footnotetext{
${ }^{1}$ The abbreviations of the Hungarian names of the institutes are given in brackets.
} 
Figure 1 shows that while the average annual frequency of heat waves increased in Budapest in the past 30 years compared to the interval of the past 100 years, it has remained practically unchanged in Debrecen. At the same time it is also obvious that heat waves are much more frequent and as a general rule, also last significantly longer in Budapest. The figure also shows that Budapest produced what by today's standard an „extremely" long is, a 12-day heat wave that, nevertheless, fades in proportion compared to the events of the entire period. In our enquiry we often came across with such remarkably outstanding yet infrequently occurring events which, notwithstanding, require attention because of their extreme values that are usually in the background of meteorological catastrophes.

Now let us examine the distribution of heat waves in the case of the scenarios of the three different model runs described earlier. Figure 2 shows the distribution of the length of the heat waves - defined by the NPHMOS - with different lengths but of at least 3 days, in the case.

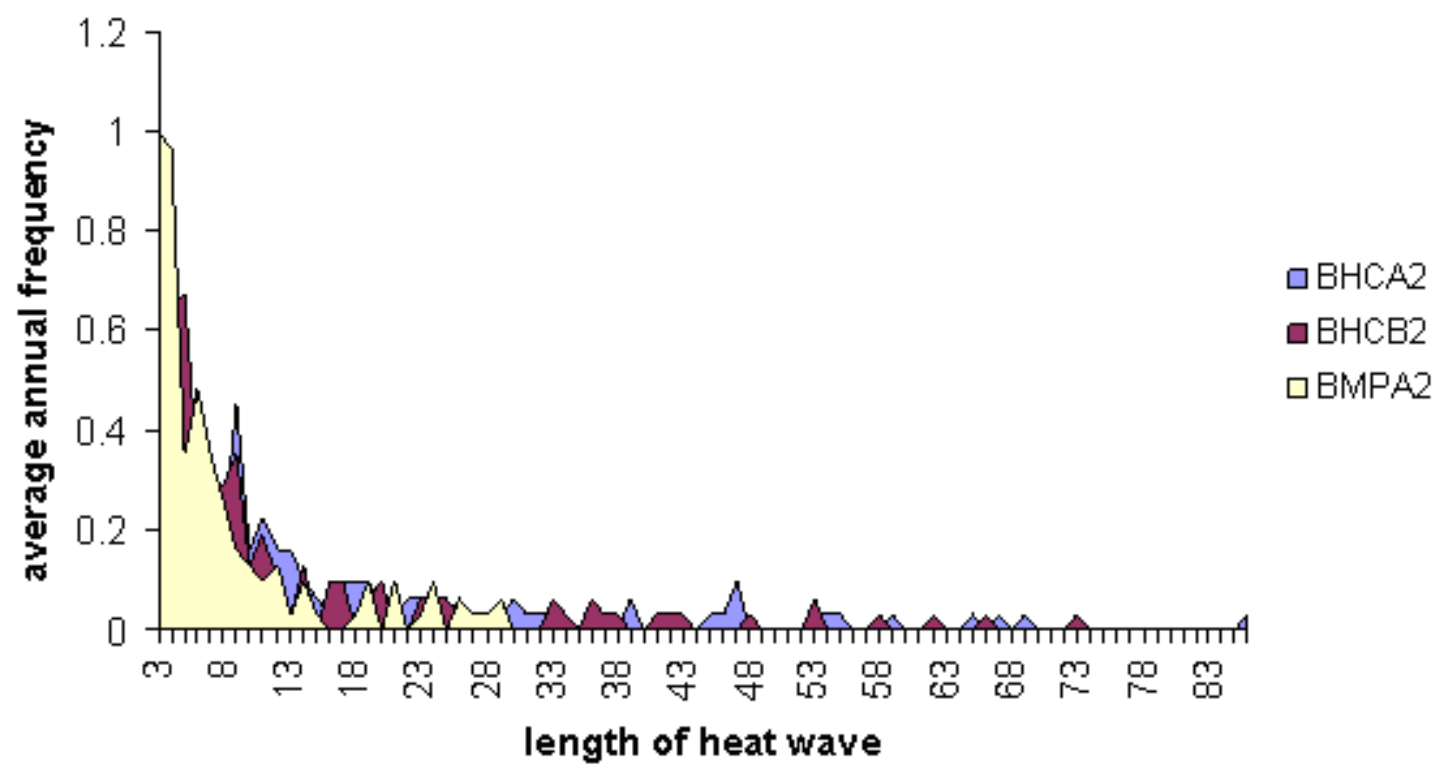

Figure 2.Distribution of heat waves in Budapest in 2070-2100 based on the NPHMOS definition (B-Budapest, HC-Hadley Center, MP-Max Planck Institute)

The difference is remarkable. Heat waves are expected not only to be more frequent but they will also be extremely protracted in length. Against the historical data, a 12-day heat wave can be regarded as of extreme length, heat waves with length of $1-2$, or even 3 months are relatively frequent in the HC runs. As a matter of fact, this means that in some of the modelled future years the whole summer is an only long heat wave. Although results of the MP appear to be essentially more steady, we should note that frequency values as well as the lengths of heat waves may double or in some cases even treble in the future. We come to similar result by examining the case of Debrecen (Fig. 3 ) The frequency values are very close to each another, however, the proportion of the occurrence of heat waves shows considerable growth. The same can be recognized in the length of heat waves. In both cases a tenfold growth may be reached and in some cases exceeded. A comparison of the diagrams of the cities reveals significant similarity in both the outstanding values and the values of great frequency. 


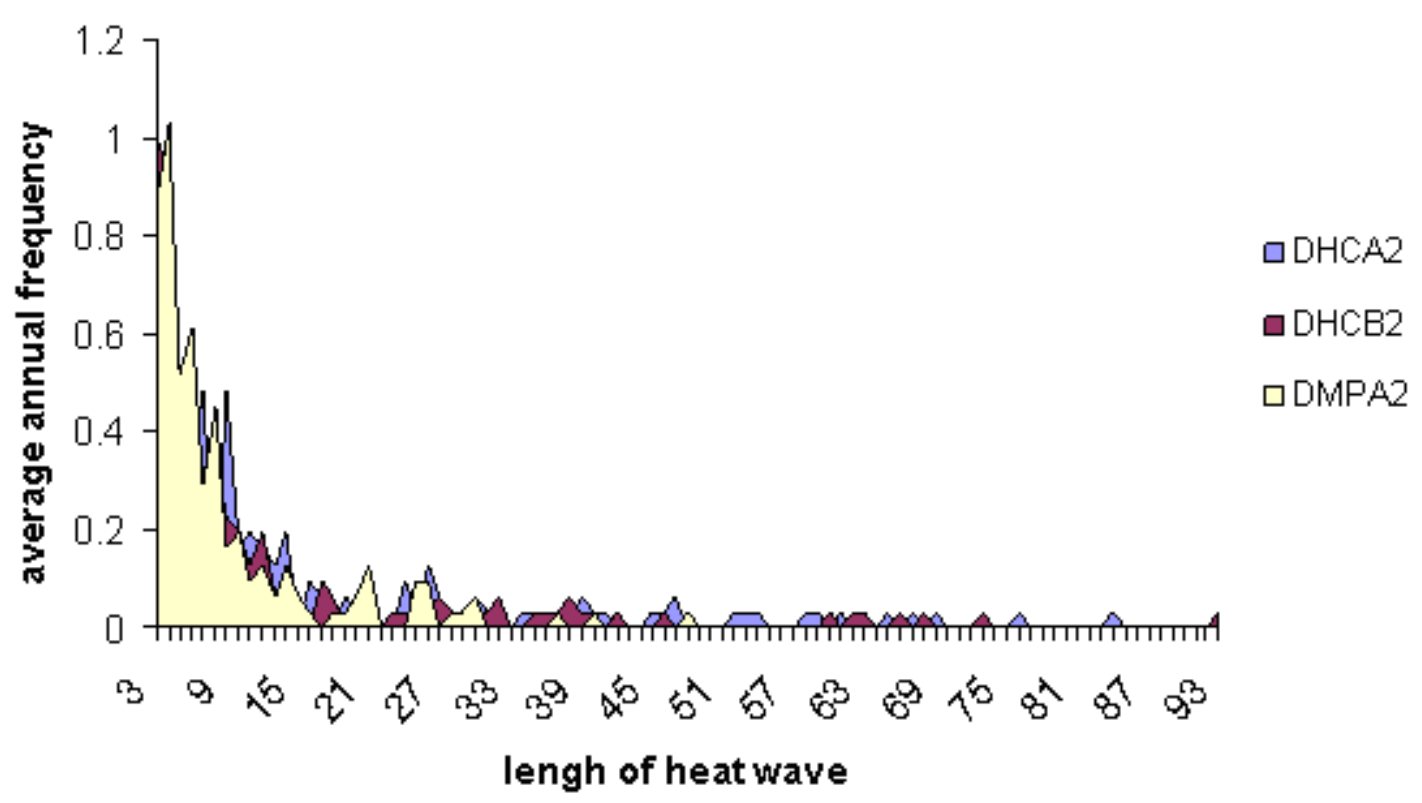

Figure 3. Distribution of heat waves by the NPHMOS definition in Debrecen in 2070-2100 (B-Budapest, HC-Hadley Center, MP-Max Planck Institute)

This is presumably explained by the fact that the expected heat waves, rather than appearing as heat islands, will have a geographically large expansion. In other words, from the point of view of the extreme values the year under scrutiny is more important than the place of examination. To support this allegation let us look at two comparative figures for the model runs producing the highest and lowest frequencies (Fig. 4 and 5).

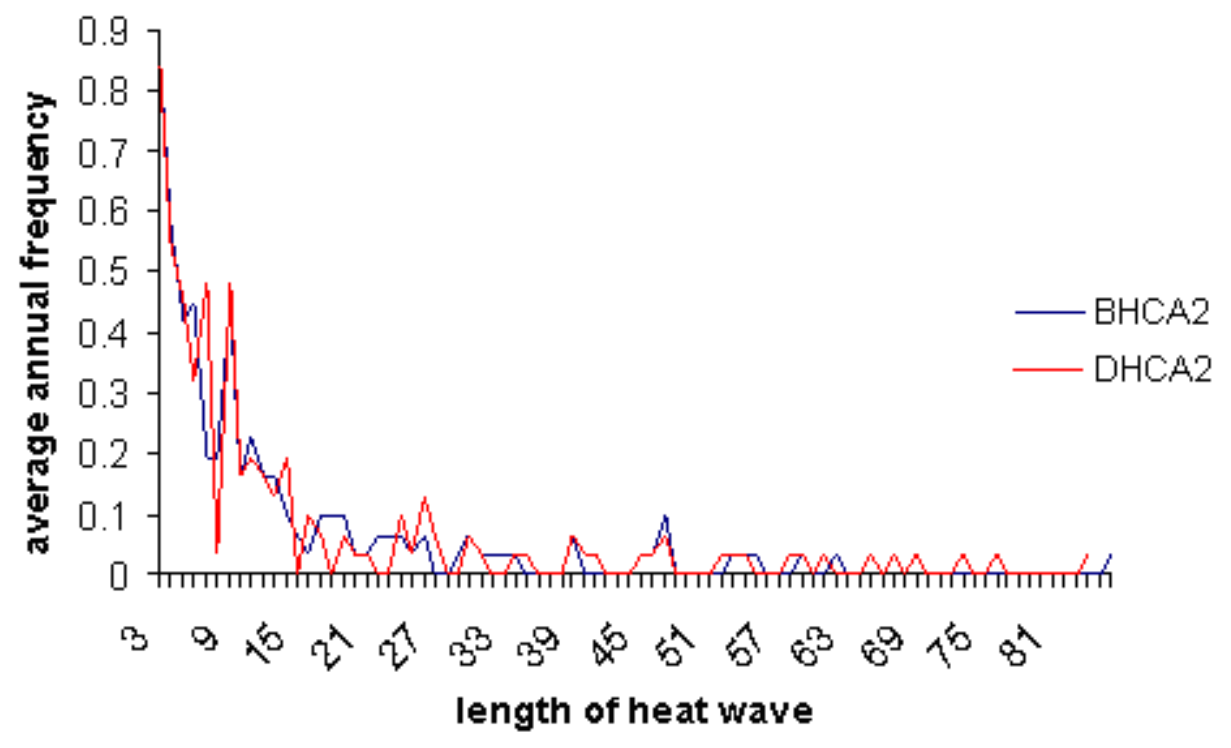

Figure 4. Distribution of heat waves in Budapest and Debrecen between 2070-2100 with the A2 model run of the Hadley Centeron the basis of the NPHMOS definition 


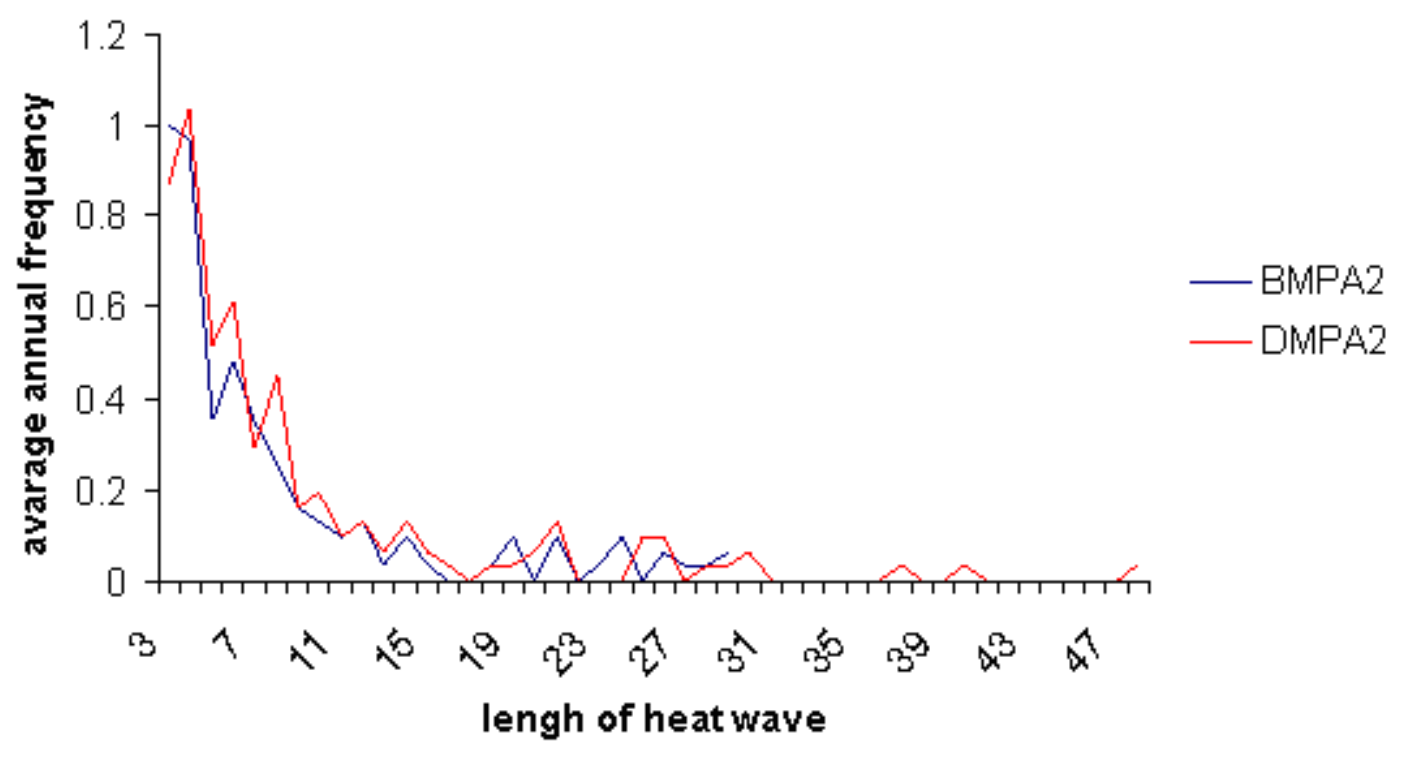

Figure 5. Distribution of heat waves in Budapest and Debrecen between 2070-2100 with the A2 model run by the Max Planck Institute based on the NPHMOS definition

It can be seen in both figures that while the characters of the curves are identical, their values are also more or less the same regardless of which model run we consider. This, in essence, supports our presumption that heat waves depend much more on global meteorological conditions than on geographical distances. To prove this allegation it might be worth to examine several other towns, but in the absence of data, we need to delay this study.

Another question of interest is the average annual number of heat wave stricken days in the historical data and in the model runs. This is an important figure, because quite obviously, long but rarely occurring events must have a greater weight than shorter heat waves when considering risk factors. It can be seen that there is a dramatic rise in the number of heat wave stricken days regardless of what basis we select or which town we examine (Fig. 6). It can also be seen that the model runs influence the occurrence of events more than the scenarios themselves do, as in the case of both cities, the difference between scenarios A2 and B2 is smaller than the difference between the same scenarios of the two institutions. It is quite peculiar that in the case of the model runs, the value of standard deviation is around 20 days, although the mean value is between 40 and 80. The average values of Debrecen are just a little over those of Budapest which is all the more remarkable, as the values shown by the historical data are by and large „negligible" when compared to future values, yet, it can be seen that the situation used to be just the opposite in the past. Regarding the historical values, the uncertainty is reflected in the fact that the standard deviation exceeds the average value in every case, which makes clear that heat wave days in the past are connected to the „warmer years”. In other words, in some years there were several heat waves, while in others there were none. The values generated by the model runs show nothing like that. Relative deviation is much smaller than in the case of the historical set of data, which clearly amounts to state that it is not possible to predict the exact number and length of heat waves in the various scenarios, while the number of heat wave days can be forecasted with ,relatively great" accuracy. 


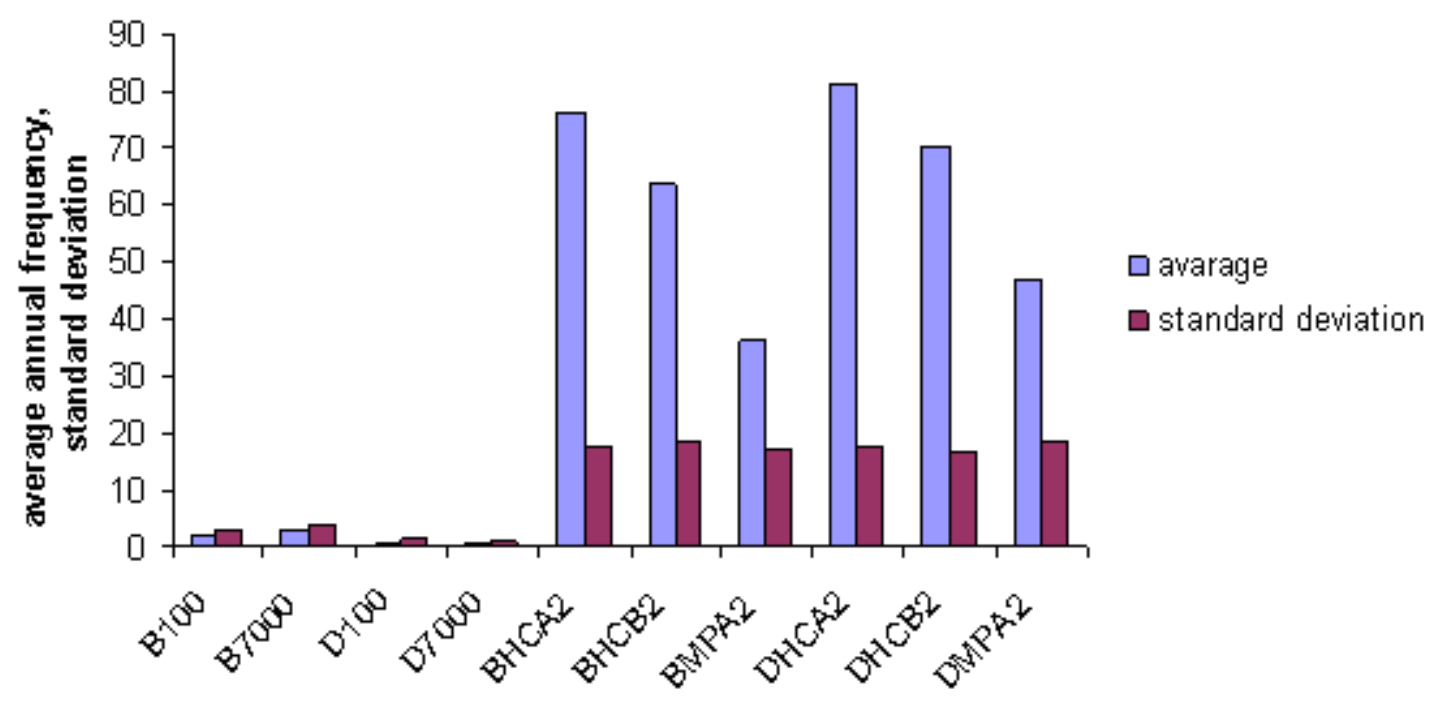

Figure 6. Average number of heat wave days and their standard deviation in the historical set of data and model runs based on the NPHMOS definition

\section{Examining the intensity of heat waves}

As mentioned earlier in my description of the relevant definitions, although heat wave is a term we can easily define from a human point of view and we can also safely say when a heat wave alarm should be called, the definitions contain no information whatsoever on the intensity of heat waves. But as the intensity of a heat wave might determine its varying effect on humans, animals, plants or the infrastructure and the economy, it is worth to examine the intensity as well as the length of each heat wave. Therefore we plotted the distribution of the outlier temperature values of the most typical three base periods used in climate research (1901-2000, 1960-1990, 1970-2000). In our first study we examined maximum temperatures instead of the usual average temperatures, as extremely high values stand out more clearly in this sample. Figure 7 shows the distribution of the above mentioned three time intervals cumulated by temperature levels, revealing, in other words, in the period the average annual number of ,heat waves" lasting for t days and characterized by a temperature of at least T. In this classification we did not yet narrow down the definition of a heat wave to events that would last for at least three days.

Based on the chart it is difficult to draw a line of distinction between the three distributions. It can be seen that the highest values, surprisingly, are contained in the 100 year set of data; but its decreasing phase is steeper than in the case of the other two diagrams (this means that outstandingly warm periods occurred not only at the end of the 20th century but also before that, but the heat waves experienced by the end of the century were either warmer or longer than the earlier ones), although the difference is insignificant. As seen on the scales of the figures, the classification involves maximum temperature levels over $30^{\circ} \mathrm{C}$, because this is roughly the level where the daily average also exceeds the threshold of heat wave alarm. 


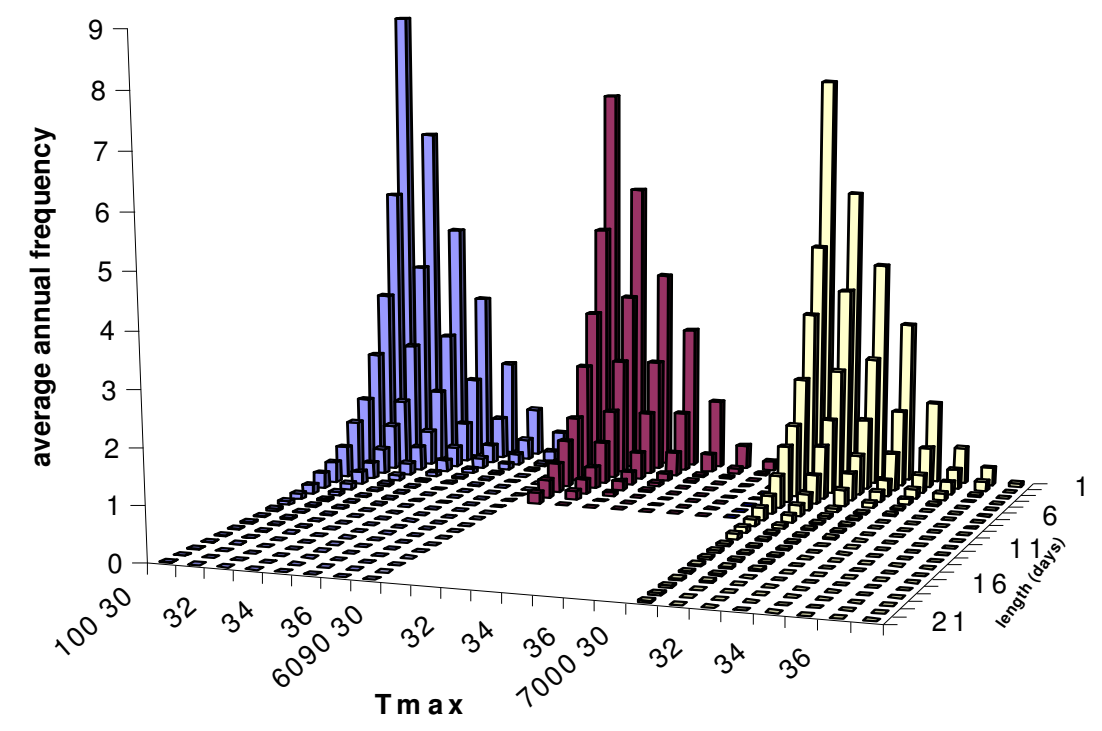

Figure 7. Distribution of the length and intensity of the maximum temperature "heat waves" for the three base periods, cumulated by temperature levels

We carried out the same enquiry also for the three model runs (Fig. 8). The difference is too striking to need any further explanation.

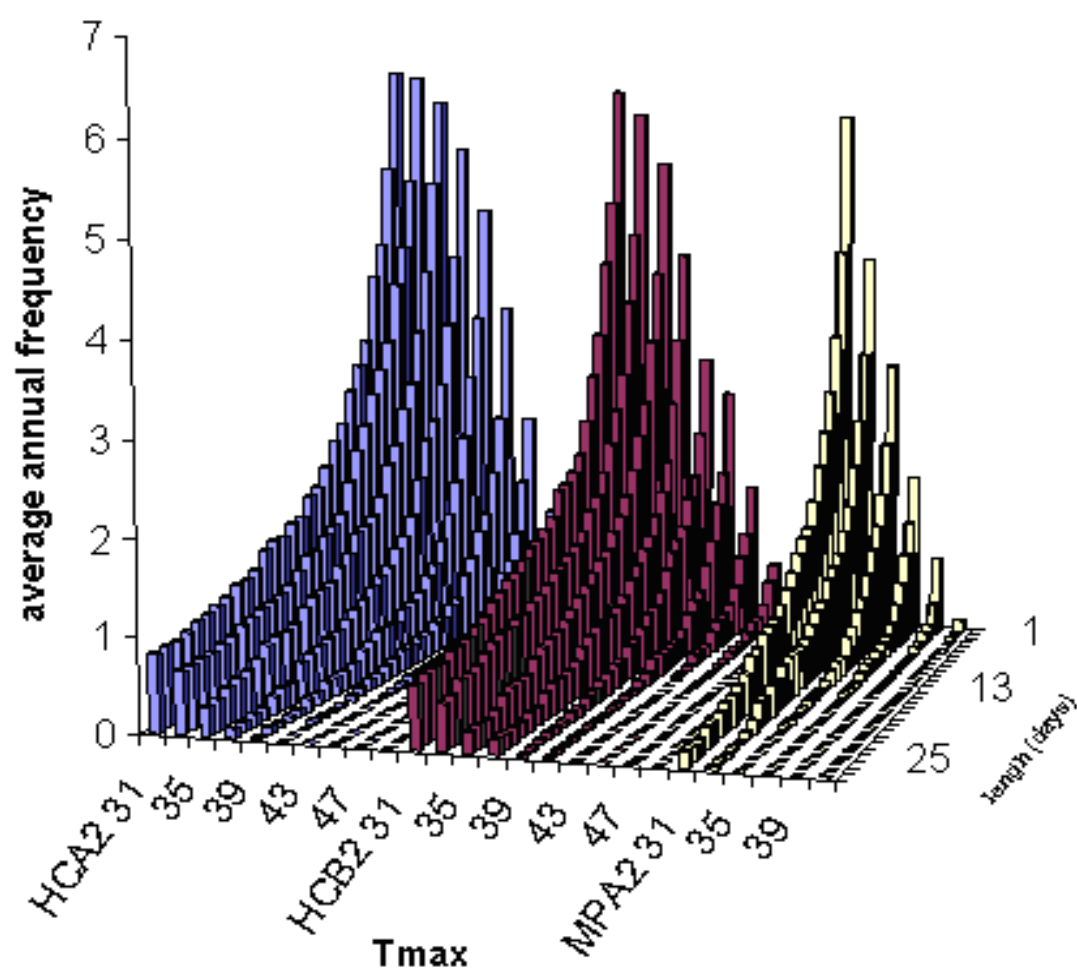

Figure 8. Distribution of the length and intensity of the maximum temperature "heat waves" of the three model runs in Budapest (2070-2100), cumulated by temperature levels 
All one might say is that the values have grown to such an extent that for technical reasons we could not represent frequencies in one and the same scale, as the $30^{\circ} \mathrm{C}$ value was accompanied by an extremely protracted length of time (even as it is, we can only show the values in a reduced scale), while on the other hand, we found we had such high temperature levels that in the interest of representation we had to desist from using a $1^{\circ} \mathrm{C}$ scale unit.

It can be clearly seen that of the three model runs frequency values were the lowest in the case of MPA2 and the highest with HCA2. To be able to compare the two HC scenarios, we drew up a figure of the differences of the frequencies (Fig. 9) which shows that with a slight exception, individual frequency values are higher in HCA2 than in B2.

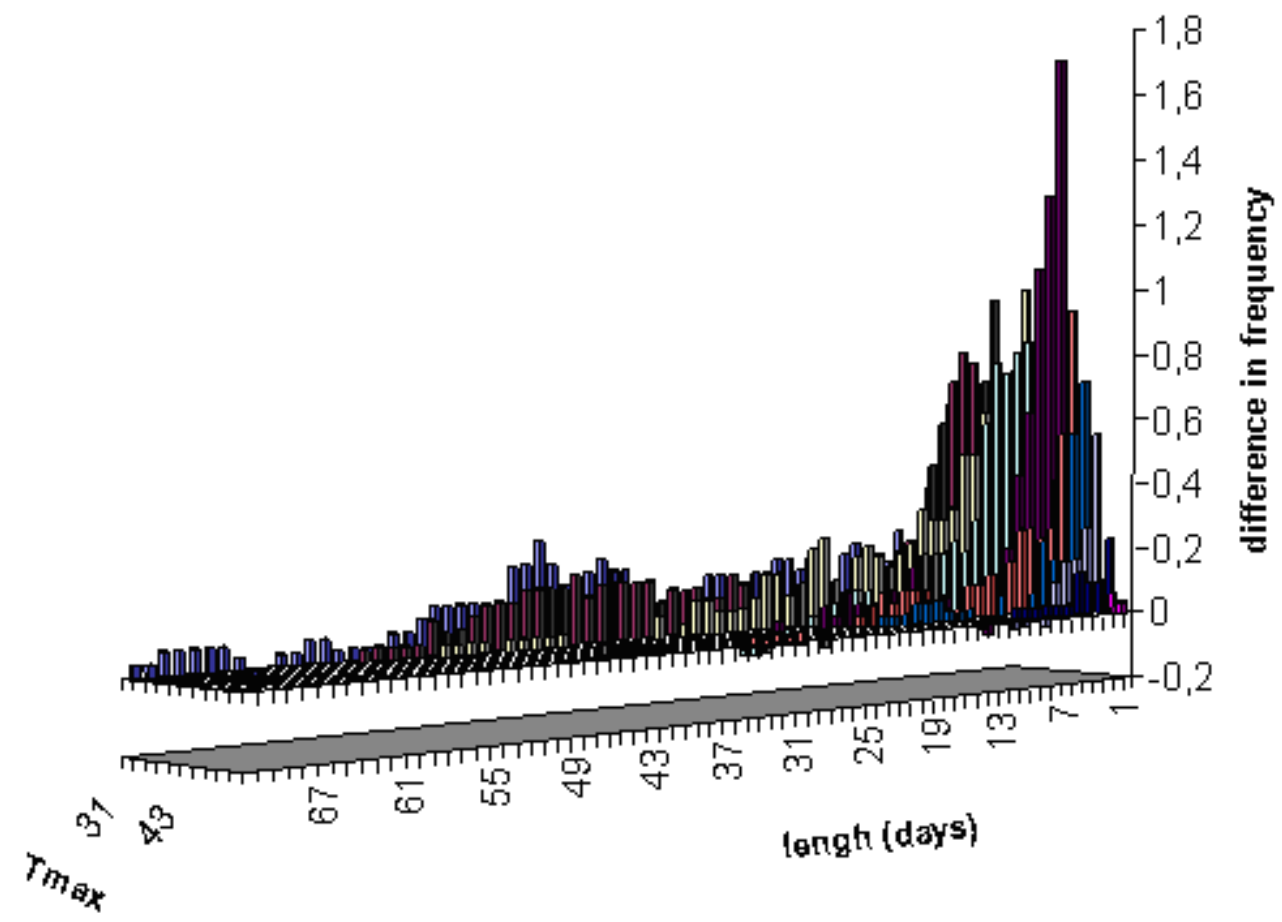

Figure 9. Differences in the frequencies of the HCA2 and HCB2 runs

Yet, to be able to make some comparison, we produced a „best case” comparison, comparing the distribution of the highest frequency values (100 year) with the run of the model (MPA2) with the lowest values of frequency ( Figure 10). All its interpretation may require is to say that had we represented three-day events that are now regarded as standard, the heat waves of the historical data could practically not be seen in the Figure, being so small in size by comparison to the data of the scenario. 


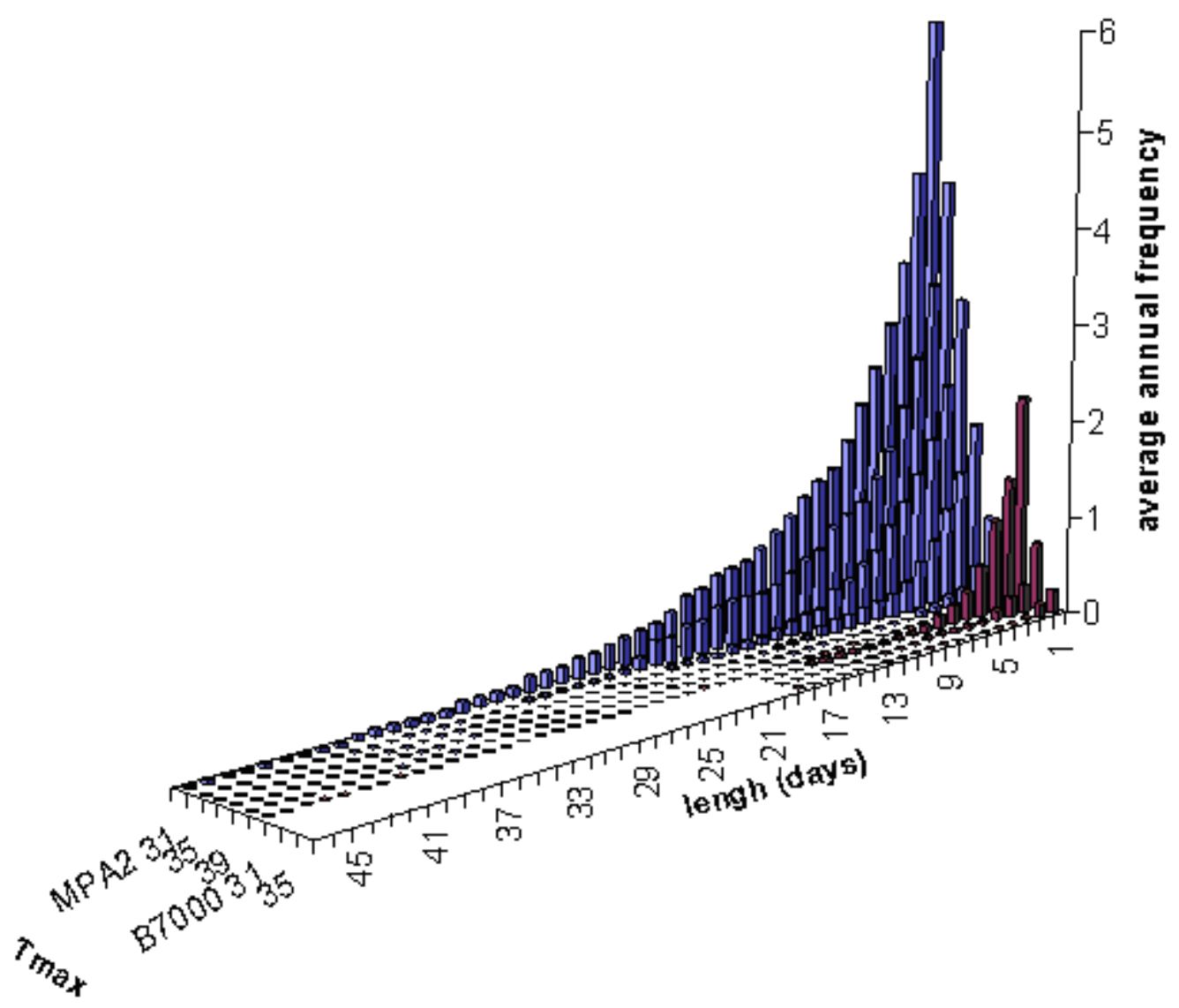

Figure 10. Comparison of the heat waves of MPA2 and the set of historical data from 1901-2000.

Finally, here is a comparison of the numerical data of some past and expected "future" events:

- The longest $31^{\circ} \mathrm{C}$ maximum temperature heat wave we have had lasted for 18 days in the past and lasts for 87 days in the runs.

- In the case of heat waves lasting for at least three days the highest maximum temperature recorded was $37^{\circ} \mathrm{C}$ in the past while the runs envisage ones of $49^{\circ} \mathrm{C}$.

- Past records show heat waves with a maximum temperature reaching or exceeding $31^{\circ} \mathrm{C}$ and lasting for at least 3 days lasting on average for 10.1 days, as opposed to some of the runs with an average reaching 92.5 days.

These are quite staggering figures. Considering these three data alone, they might mean that in case the scenarios come true, practically the whole summer will be one long heat wave, with its peaks higher by $12^{\circ} \mathrm{C}$ when we come to the period between 2070 and 2100. This appears unbelievable at first glance, for these scenarios envisage an average temperature rise of "only" $5-6^{\circ} \mathrm{C}$ at worst.

\section{Average temperatures in Budapest}

To find out whether the rise of $12^{\circ} \mathrm{C}$ mentioned in the previous chapter is possible, we examined the succession of minimum, maximum and average temperatures in Budapest in the HCA2 and MPA2 model runs (that offer the two extremes in way of the 
data) and in the historical records (where we considered what the latest research also relies on, the period between 1970-2000). We made several comparisons, the most expressive of which are seen in Figure 11.
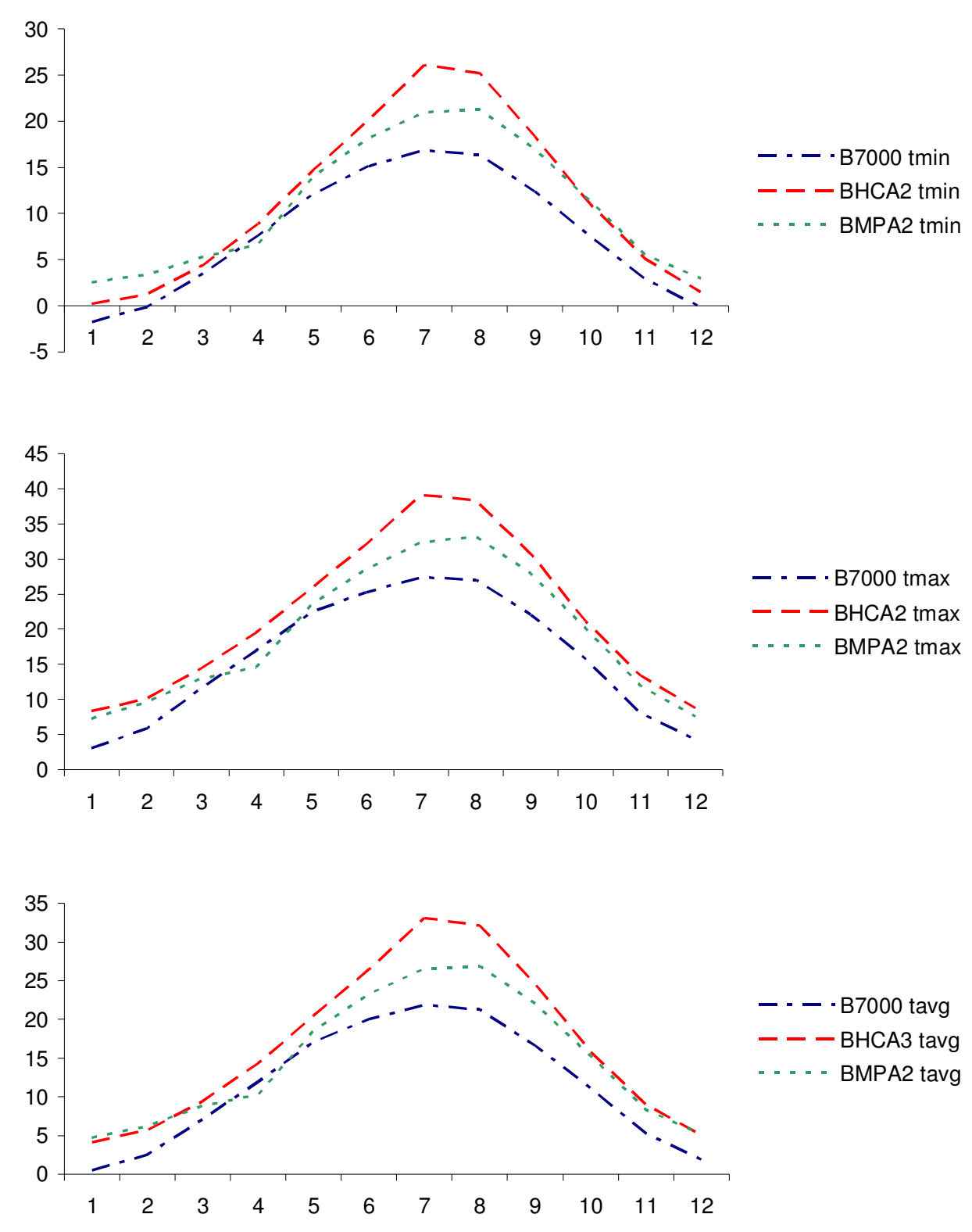

Figure 11. $a, b, c:$ Monthly average of minimum, maximum and average temperatures in Budapest in the 1970-2000 period in case of historical data, and in the 2070-2100 period in the case of runs of the HCA2 and MPA2 models

It is clear that with the exception of the figures for April, the historic time series data have always shown the lowest values. That was followed by the MPA2 run, as heat value highs appear in HCA2. In other words, the biggest differences appear between the set of historical data and HCA2. (Tab. 1) 
Table 1. Difference between the 31 year average of monthly minimum, maximum and average temperatures of the HCA2 run and the 1970-2000 time series

\begin{tabular}{c|c|c|c}
\hline & Tmin & Tavg & Tmax \\
\hline Januar & 1,98 & 3,68 & 5,27 \\
Februar & 1,40 & 3,18 & 4,35 \\
Mach & 0,89 & 2,27 & 2,83 \\
April & 1,25 & 2,39 & 2,57 \\
May & 2,62 & 3,42 & 3,44 \\
June & 4,96 & 6,46 & 6,85 \\
July & 9,21 & 11,23 & 11,79 \\
August & 8,87 & 10,89 & 11,36 \\
September & 5,94 & 7,92 & 8,67 \\
October & 3,47 & 4,71 & 5,41 \\
November & 2,18 & 3,71 & 5,36 \\
December & 1,66 & 3,17 & 4,55 \\
\hline yearly & $\mathbf{3 , 7 0}$ & $\mathbf{5 , 2 5}$ & $\mathbf{6 , 0 4}$ \\
\hline
\end{tabular}

No deep-going analysis is required to find the solution. According to the HCA2 model run, the maximum temperature in July will be warmer by $11.8^{\circ} \mathrm{C}$ than the average of the last 31 years of the last century. It is no exaggeration to say that this is a dramatic value. Its appearance in real life stresses even perfectly healthy individuals while it is harmful for the diseased and it induces high ecological and economic risk. At the same time it can be seen that while winter would also be warmer, warming in spring might not be significant compared to the annual average. It is interesting, however, that the rise of the values is essentially smaller in the case of minimum temperatures, although the rise of $9.2^{\circ} \mathrm{C}$ in July is just as catastrophic as the value emerging in the maximum temperatures.

\section{Minimum temperature heat waves}

In Section "Examining the intensity of heat waves" we discussed heat waves defined by maximum temperatures, Extreme events are of high risk on days with extreme hot noon hoursOn a day with extremely high maximum temperature the average cannot be low either, as in continental zone high fluctuations of temperature is not characteristic. On the other hand, one might ask: how cold are the nights of hot days? Do houses cool down enough for people to get the rest and recovery they need during the night? Naturally, this question can also be turned to form a statement: if nights are hot, presumably the days are hot too, and so you can also define a heat wave manifesting itself in high minimum temperatures which is just as unpleasant as those expressed in maximum temperatures. (Note that there is a significant overlapping between them.)

Analogously, we performed the same examinations with minimum temperature heat waves that we did with maximum temperature heat waves. In their tendencies, the results fully corresponded with earlier results. Admitthat the frequencies of the heat waves in the three model runs show larger differences than what we experienced in the case of maximum temperatures, but regarding frequency values we can set up the order of HCA2, HCB2 and MPA2 (Fig. 12) again. A comparison of the historical records and the most favourable MPA2 data also reveals differences in magnitude, even if those differences are somewhat smaller than in the case of maximum temperatures (Fig. 13). 
Naturally, Table 1. explains why these differences are smaller in the case of the minimums than in that of the maximums.

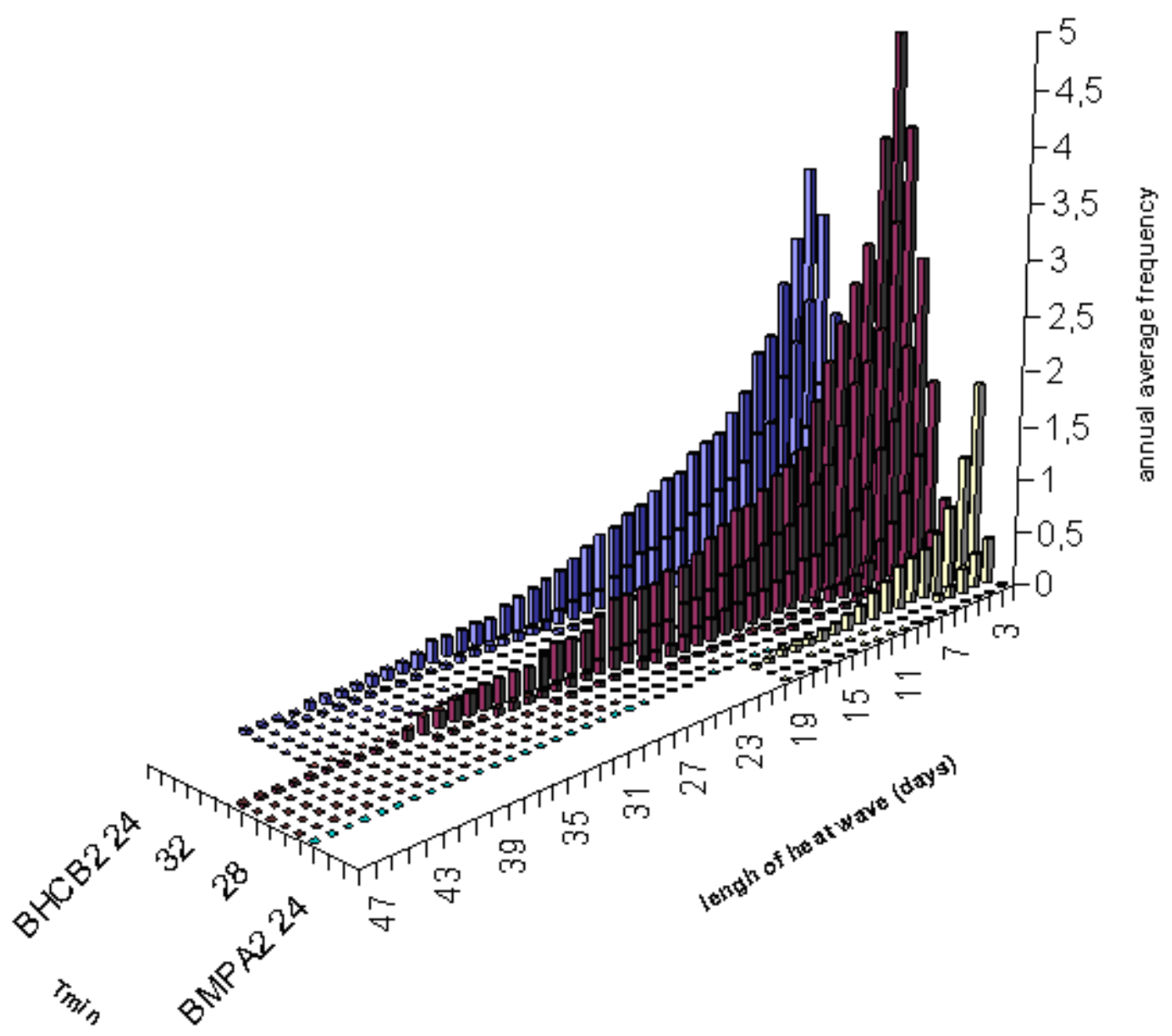

Figure 12. Distribution by minimum temperature levels of the heat waves considering minimum temperatures in Budapest in case of the three model runs

In the minimum temperature category, we examined heat waves with a minimum temperature of over $24^{\circ} \mathrm{C}$ in the scenarios and those of over $18^{\circ} \mathrm{C}$ in the case of the historical data. We have chosen this value because it is agreed in scientific literature that it is difficult for the human body to regenerate above normal room temperature which would be $24^{\circ} \mathrm{C}$, but because of the heat island effect of towns, the temperature in homes is warmer than air temperature by $5-6^{\circ} \mathrm{C}$, therefore $18^{\circ} \mathrm{C}$ is not necessarily "pleasant" in a town. However, there was no point in examining this value in the model runs, because we would have arrived at heat waves of several months. 


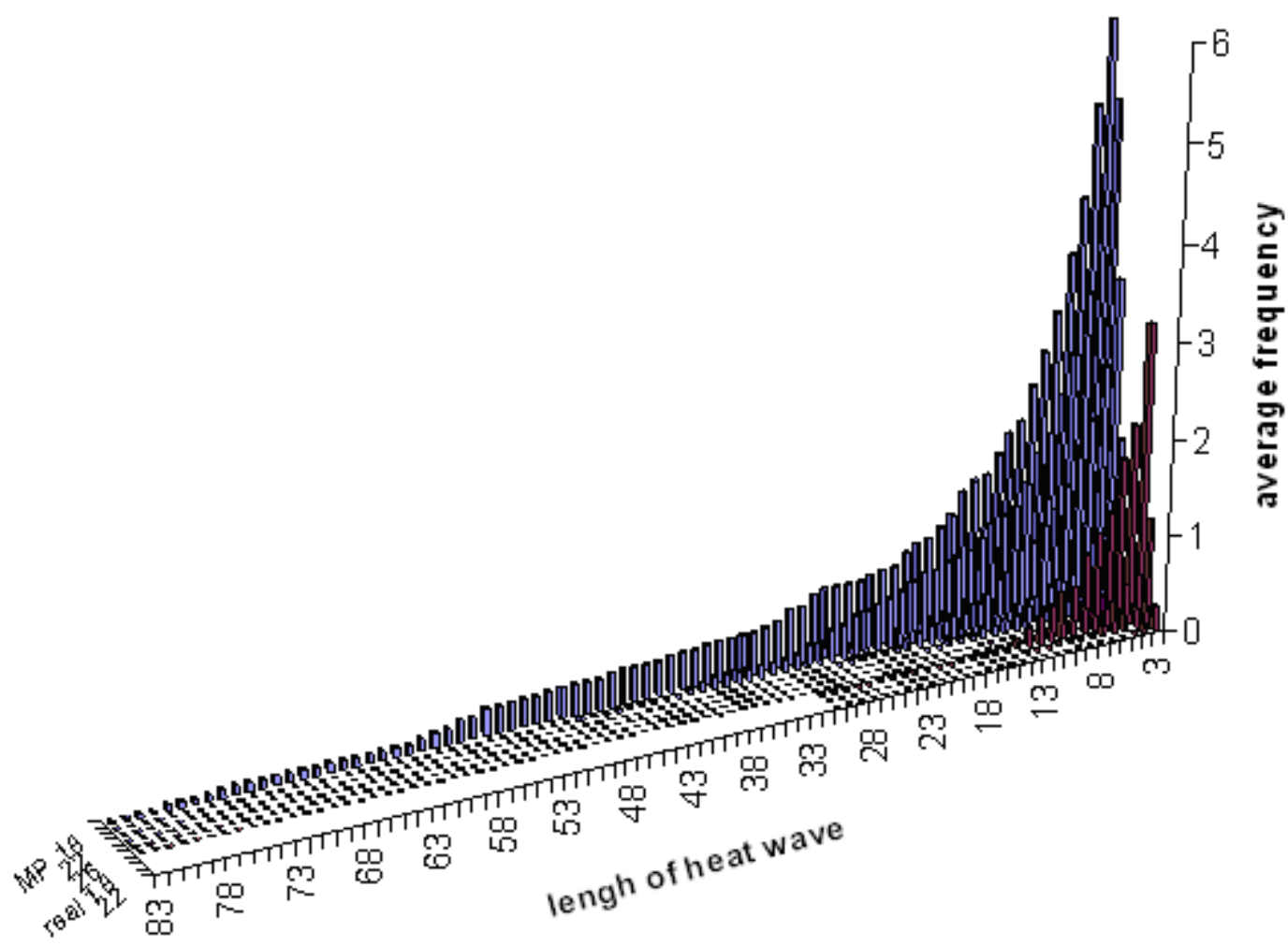

Figure 13. „Best case” comparison of the distributions cumulated by temperature levels of the heat waves considering minimum temperatures in Budapest using 1970-2000 and MPA2 data

Finally, let us compare these heat waves, too, with some numerical data:

- The highest minimum temperature heat wave experienced was $21^{\circ} \mathrm{C}$ based on historical data, but model runs also predict ones of $34^{\circ} \mathrm{C}$.

- The longest $18^{\circ} \mathrm{C}$ heat wave was one month long in the historical data. Even the most favourable scenario contained an $18^{\circ} \mathrm{C}$ heat wave lasting for 87 days.

- The number of heat wave days has also shown a drastic increase. This value is practically incomparable as in the historical data the minimum temperature was above $18^{\circ} \mathrm{C}$ for at least 3 days on an annual average of only 19 days, while the model runs contain spells of over 40 days when the minimum temperature does not go under $24^{\circ} \mathrm{C}$.

I believe that the use of any of the above three heat wave definitions might substantiate the allegation made in the introduction, namely that the climate in Hungary will change and extreme events caused risks of all kinds will multiply if the scenarios we have studied and discussed become a reality. Heat waves are among the most dangerous of extreme meteorological events. Whichever definition we use, we can say that the length and intensity of heat waves will increase considerably with high possibility and it might entail unforeseeable consequences for several sectors. 


\section{REFERENCES}

[1] Beniston, M., Diaz, H.F.(2004): The 2003 heat wave as an example of summers in a greenhouse climate? Observations and climate model simulations for Basel, Switzerland. - Global and Planetary Change Volume 44, Issues 1-4, 73-81. pp.

[2] Harnos, Zs. (2007): Klímaváltozással összefüggő hazai kutatások: a VAHAVA folytatása. - „KLÍMA-21” Füzetek 2007.49.: 3-15. pp.

[3] Horváth, L., Gaál, M. (2006): Spatial analogies in service of climate change analysis 6th Annual Meeting of the EMS / 6th ECAC 4 - 8 September 2006 Ljubljana, Slovenia abstract cd-rom.

[4] Horváth, L., Gaál, M., Solymosi N. (2007): Spatial analogues in climate change research - EFITA/WCCA 2 - 5 July 2007, Glasgow, Scotland, Paper CD ROM p22.

[5] IPCC (2007): Fourth Assessment Report "Climate Change 2007"

[6] Poumadère, M., Mays C., Le Mer, S., Blong, R. (2005): The 2003 Heat Wave in France: Dangerous Climate Change Here and Now. - Risk Analysis Volume 25 Issue 6. 14831494.pp.

[7] PRUDENCE (2007): Prediction of Regional scenarios and Uncertainties for Defining EuropeaN Climate change risks and Effects, http://prudence.dmi.dk.

[8] Schär C., Vidale, P.L., Lüthi, D., Frei, C., Häberli C., Liniger M.A., Appenzeller, C. (2004): The role of increasing temperature variability in European summer heat waves. Nature 427, 332-336 pp.

[9] Solymosi, N., Maróti-Agóts, Á., Ózsvári, L., Könyves, L., Horváth L., Kern A. (2007): Region specific heat stress forecastfor cattleproduction based on climatechange. GISVET'07, Coppenhagen, 22-24 August 2007.

[10] Szenteleki K. (2007): A KKT programrendszer leírása - „KLÍMA-21” füzetek - impress

[11] Szenteleki K., Ladányi M., Erdélyi É., Horváth L., Hufnagel L., Révész A. (2007): A KKT klímakutatás adatbáziskezelő szoftver bemutatása - Georgikon Konferencia, Keszthely 5 pp.

[12] Szenteleki, K., Ladányi, M., Szabó, É., Horváth, L., Hufnagel L., Solymosi, N., Révész, A. (2007): Introducing the KKT climate research database management software EFITA Conference, Glasgow.

[13] World Meteorological Organization, http://www.wmo.ch.

[14] Állami Népegészségügyi és Tisztiorvosi Szolgálat, http://www.antsz.hu.

[15] National Weather Service, http://www.nws.noaa.gov. 